\title{
PENGARUH PENERAPAN CORPORATE SOCIAL RESPONSIBILITY TERHADAP PROFITABILITAS PERUSAHAAN MANUFAKTUR YANG TERCATAT DI BEI
}

\author{
Anita Erari ${ }^{1}$ \\ aerari@yahoo.co.id \\ Fitri Nurjanah ${ }^{2}$ \\ fitrinurj15@gmail.com \\ 1-2 Fakultas Ekonomi dan Bisnis Universitas Cenderawasih
}

\begin{abstract}
Abstraksi:
Tujuan penelitian ini adalah untuk menganalisis praktek penerapan tanggung jawab sosial pada perusahaan manufaktur sub sector food and beverage dan untuk menguji pengaruh penerapan tanggung jawab social perusahaan terhadap profitabilitas. Data yang digunakan dalam penelitian ini adalah laporan keuangan tahun 2014-2018. Populasi sebanyak 18 perusahaan yang dipilih menggunakan metode purposived sampling. Model analisis yang digunakan adalah regresi linier sederhana dan pengujian hipotesis menggunakan uji T untuk menguji koefisien regresi parsial. Hasil analisis data menunjukkan bahwa tingkat penerapan Corporate Social Responsibility (CSR) tidak berpengaruh terhadap pada return on asset (ROA) dan return on equity (ROE) pada perusahaan, tetapi Corporate Social Responsibility (CSR) berpengaruh terhadap Net Profit Margin (NPM) perusahaan dengan nilai signifikan 0,003 lebih kecil dari 0,05. Kemampuan prediksi dari tiga variabel tersebut terhadap CSR sebesar $18 \%$ sebagaimana ditunjukkan oleh besarnya adjusted $\mathrm{R}$ square sebesar $18 \%$ sedangkan sisanya $82 \%$ dipengaruhi oleh faktor lain yang tidak dimasukkan ke dalam model penelitian ini.
\end{abstract}

Kata Kunci : Corporate Social Responsibility, Profitabilitas, ROA, ROE, NPM.

\section{PENDAHULUAN}

Perusahaan sebagai pelaku ekonomi, apapun bentuk industrinya, bertujuan untuk mencetak laba yang optimal guna meningkatkan kekayaan pemilik saham dan juga kinerja keuangan perusahaan akan tetapi itu saja tidak cukup, Sundari (2011) menjelaskan bahwa keberlanjutan bisnis perusahaan tidak terjamin bila hanya mengandalkan laba yang tinggi semata, tetapi perusahaan juga harus memiliki komitmen yang tinggi dalam menjalankan program CSR (Corporate Social Responsibility).

Menurut (Siregar, 2007) CSR (Corporate Social Responsibility) merupakan salah satu kewajiban yang harus dilaksanakan oleh perusahaan sesuai dengan isi pasal 74 Undang-Undang Perseroan Terbatas (UUPT) yang terbaru, yakni UU Nomer 40 Tahun 2007. Melalui undang-undang ini, industri atau koprasikoprasi wajib untuk melaksanakanya, tetapi kewajiban ini bukan suatubeban yang memberatkan.Perlu diingat pembangunan suatu negara bukan hanya tangungjawab pemerintah dan industri saja, tetapi setiap insan manusia berperan untuk mewujudkan kesejahteraan sosial dan pengelolaan kualitas hidup masyarakat.Industri dan korporasi berperan untuk mendorong pertumbuhan ekonomi yang sehat dengan mempertimbangkan pula faktor lingkungan hidup.

Melihat pada kondisional semcam ini maka penulis mencoba mengangkat permasalahan ini kepermukaan.Penulis (Asy'ari, 2009) menganggap bahwa pengambilan judul diatas cukup strategis. Pertama, sebab sebenarnya konsep tanggungjawab sosial perusahaan telah dikenal sejak awal 1970, yang secara umum diartikan sebagai kumpulan kebijakan dan praktik yang berhubungan dengan stakeholder, nilai-nilai, pemenuhan ketentuan hukum, penghargaan masyarakat, lingkungan, serta komitmen dunia usaha untukberkontribusi dalam pembangunan secara berkelanjutan. Seiring perjalanan waktu, di satu sisi sektor industri atau koprasi-koprasi skala besar telah mampu memberikan kontribusi terhadap pertumbuhan ekonomi nasional, tetapi di sisi lain ekploitasi sumber-sumber daya alam oleh sektor industri sering kali menyebabkan kerusakan lingkungan. Kedua, adalah sebagai upayauntuk menegaskan hubungan perusahaan dengan aktifitas perniagaan yang diselenggarakan oleh para perusahaan.Dalam konteks perniagaan yang diselenggarakan terdapat hubungan timbal-balik antara personal perusahaan secara internal dan antara internal perusahaan dengan masyarakat luar perusahaan. 


\section{LANDASAN TEORI}

\section{A. Kajian Teori}

1. Corporate Social Responsibility

CSR merupakan suatu konsep terintegrasi yang menggabungkan aspek bisnis dan sosial dengan selaras agar perusahaan dapat membantu tercapainya kesejahteraan para Stakeholder, serta dapat mencapai profit maksimum sehingga dapat meningkatkan harga saham (Nugraha,2011:23).

\section{Rasio Profitabilitas}

Menurut Septiana (2012:71) Profitabilitas perusahaan merupakan kemampuan perusahaan dalam menghasilkan laba bersih dari aktivitas yang dilakukan pada periode akuntansi. Laba merupakan gambaran mengenai kinerja yang dicapai dari proses transaksi umum yang dilakukan perusahaan selama periode tertentu. Laba dijadikan indikator bagi para stakeholder untuk menilai sejauh mana kinerja manajemen dalam mengelola suatu perusahaan. Tingkat kemampuan perusahaan dalam memperoleh keuntungan dapat dilihat dan diukur dengan cara menganalisa laporan keuangan melalui rasio profitabilitas.

Jenis-jenis rasio profitabilitas yaitu :

a. ROA : Menurut Sartono (2001:68) Return on Assets menunjukkan kemampuan perusahaan menghasilkan laba dari aktiva yang dipergunakan. Return on Asset (ROA) mengukur berapa persentase laba bersih sesudah pajak terhadap total aset perusahaan tersebut. Dengan mengetahui rasio ini, dapat dinilai apakah perusahaan telah efisien dalam memanfaatkan asetnya dalam kegiatan operasional perusahaan.Rasio ini juga memberikan ukuran yang lebih baik atas profitabilitas perusahaan, karena menunjukkan efektivitas manajemen dalam menggunakan aset untuk memperoleh pendapatan.

b. ROE : Menurut Sartono (2001) Return on asset adalah rasio yang mengukur kemampuan perusahaan memperoleh laba yang tersedia bagi pemegang saham perusahaan. Rasio ini dipengaruhi oleh besar kecilnya utang perusahaan, apabila proporsi utang makin besar maka rasio ini juga akan besar. Untuk melakukan analisis profitabilitas yang merupakan hasil akhir dari berbagai kebijakan dan keputusan yang dijalankan perusahaan, dibutuhkan angka indikator.Analisis profitabilitas ini memberikan gambaran tentang efektif tidaknya suatu perusahaan. Profitabilitas dapat diukur melalui kemampuan perusahaan mempertahankan kebijakan deviden yang stabil sementara di saat yang sama dapat mempertahankan kenaikan kekayaan pemegang saham dalam perusahaan.

c. NPM : Menurut (Syamsuddin, 2011) Net Profit Margin adalah rasio yang digunakan untuk mengukur laba bersih sesudah pajak dibandingkan dengan volume penjualan.Apabila suatu perusahaan memiliki nilai NPM lebih dari 10\% maka perusahaan tersebut telah dianggap perusahaan dengan predikat sangat baik.Net profit margin yang tinggi menunjukkan perusahaan menetapkan harga produknya dengan benar dan berhasil mengendalikan biaya dengan baik.Dengandemikian semakin tinggi nilai NPM berarti semakin besar pula laba bersih yang didapat suatu perusahaan.

\section{METODE PENELITIAN}

\section{A. Populasi dan Sampel}

Populasi dalam penelitian ini adalah semua perusahaan manufaktur yang tercatat di BEI sub sector food and beverage tahun 2014-2018. Jumlah populasi penelitian ini adalah 18 perusahaan yang akan dieliminasi sesuai kriteria. Metode pemilihan sampel dalam penelitian ini adalah metode purposive judgement sampling, yaitu tipe pemilihan sampel secara tidak acak yang informasinya diperoleh dengan menggunakan pertimbangan tertentu.

Adapun kriteria yang digunakan dalam penentuan sampel penelitian ini adalah:

a) Perusahaan manufaktur sektor makanan dan minuman yang terdaftar di BursaEfek Indonesia pada tahun 2014-2018.

b) Menerbitkan annual report pada tahun 2014-2018 di website www.idx.co.id.

c) Mengungkapkan CSR pada annual report.

d) Memiliki data yang terkait dengan data-data yang dibutuhkan dalam penelitian ini. 
Berdasarkan kriteria diatas penelitian ini menemukan perusahaan yang dapat dijadikan sampel penelitian sebanyak 10 perusahaan manufaktur dari sub sector Food and Beverage yang terdaftar Bursa Efek Indonesia.

\section{B. Jenis dan Sumber data}

Jenis data yang digunakan dalam penelitian ini, yaitu data kuantitatif. Data yang digunakan dalam penelitian ini adalah data sekunder. dalam penelitian ini adalah Data Annual Report perusahaan manufaktur tahun 2014-2018 dari www.idx.co.id.

\section{Teknik Pengumpulan Data}

1. Metode dokumentasi, yaitu metode yang menghimpun informasi untuk menyelesaikan masalah yang ada dalam dokumen. Berupa catatan, transkip, buku, surat kabar, majalah, notulen, rapot, agenda dan sebagainya.

2. Metode studi pustaka, yaitu pengumpulan data dengan membaca buku-buku dan literatur-literatur pendukung yang relevan dengan masalah yang diteliti. Dalam pencarian teori, peneliti akan mengumpulkan informasi sebanyakbanyaknya dari keperpustakaan yang berhubungan. Sumber-sumber keperpustakaan dapat di peroleh dari : buku, jurnal, majalah, hasil-hasil penelitian (tesis dan disertasi), dan sumber-sumber lainnya yang sesuai ( intenet, Koran dan sebagainya). Dalam penelitian ini menggunakan laporan tahunan perusahaan dari tahun 2014-2018 yang di ambil dari website www.idx.co.id

\section{Metode Analisis Data}

Metode analisis data yang digunakan dalam penelitian ini berupa metode analisis kualitatif, yaitu dengan menggunakan angka rasio keuangan. Tahap-tahap analisis kualitatif yang digunakan adalah sebagai berikut :

1. CSR

Variabel ini menggunakan 78 item pengungkapan CSR oleh Sembiring (2005) dengan rumus:

Corporate SocialResponsibility $=\mathrm{n} / 78$, Dimana $\mathrm{n}=$ total index CSR yang dimiliki Perusahaan .

2. Rasio profitabilitas yang di gunakan yaitu:

a) Return on Asset merupakan rasio untuk mengukur kemampuan perusahaan dalam menghasilkan laba atas aset yang dipergunakan. Menurut (Margaretha,2011:26) rumus perhitungannya yaitu:

$$
R O A=\frac{\text { Laba Bersih Sesudah Pajak }}{\text { Total Aset. }}
$$

b) Return on Equity merupakan rasio untuk mengukur kemampuan perusahaan untuk menghasilkan laba atas modalnya sendiri. Menurut (Margaretha, 2011: 27) rumus perhitungannya yaitu:

$$
R O E=\frac{\text { Laba Bersih Sesudah pajak }}{\text { Ekuitas }}
$$

c) Net Profit Margin adalah rasio yang digunakan untuk mengukur laba bersih sesudah pajak dibandingkan dengan volume penjualan.Menurut (Syamsuddin,2011) rumus yang digunakan untuk mengukur rasio ini yaitu:

$$
N P M=\frac{\text { Laba Bersih Sesudah Pajak }}{\text { Penjualan }}
$$

\section{HASIL DAN PEMBAHASAN}

\section{A. Return On Assets (ROA)}

Variabel ROA dihitung dengan membandingkan laba bersih dengan total aktiva. Berdasarkan analisis data menunjukkan bahwa perusahaan yang memiliki nilai minimum yaitu sebesar -0,069 pada perusahaan Prasidha Aneka Niaga 
Tbk. Nilai mean tertinggi yaitu sebesar 0,249 pada perusahaan Ultra Jaya Milk Industry Tbkdan nilai mean sebesar 0,06072, Standar deviasi perusahaan sebesar 0,071662.

\section{B. Return On Equity (ROE)}

Variabel ROE dihitung dengan membandingkan laba bersih dengan total aktiva. Berdasarkan analisis data pada tabel 4.5 menunjukkan bahwa perusahaan yangmemiliki nilai minimum yaitu sebesar $-0,192$ pada perusahaan Prasidha Aneka Niaga Tbk. Nilai mean tertinggi yaitu sebesar 0,281 pada perusahaan Ultra Jaya Milk Industry Tbkdan nilai mean sebesar 0,08533, Standar deviasi perusahaan sebesar 0,107327.

\section{Net Profit Margin (NPM)}

Variabel NPM dihitung dengan membandingkan laba bersih dengan total aktiva. Berdasarkan analisis data pada tabel 4.5 menunjukkan bahwa perusahaan yangmemiliki nilai minimum yaitu sebesar -0,240 pada perusahaan Prasidha Aneka Niaga Tbk. Nilai mean tertinggi yaitu sebesar 0,151 pada perusahaan Ultra Jaya Milk Industry Tbkdan nilai mean sebesar 0,3887 , Standar deviasi perusahaan sebesar 0,71893 .

\section{Tabel 1. Hasil Uji Pengaruh Variabel CSR Secara Parsial Terhadap Return On Asset}

\begin{tabular}{|c|c|c|c|c|c|c|}
\hline \multicolumn{7}{|c|}{ Coefficients $^{\mathrm{a}}$} \\
\hline \multirow{2}{*}{\multicolumn{2}{|c|}{ Model }} & \multicolumn{2}{|c|}{$\begin{array}{c}\text { Unstandardized } \\
\text { Coefficients }\end{array}$} & \multirow{2}{*}{$\begin{array}{c}\text { Standardized } \\
\text { Coefficients } \\
\text { Beta } \\
\end{array}$} & \multirow[b]{2}{*}{ T } & \multirow[b]{2}{*}{ Sig. } \\
\hline & & B & $\begin{array}{l}\text { Std. } \\
\text { Error }\end{array}$ & & & \\
\hline \multirow[t]{2}{*}{1} & (Constant) & 0.246 & 0.012 & & 20.667 & 0 \\
\hline & ROA & 0.208 & 0.127 & 0.229 & 1.63 & 0.11 \\
\hline
\end{tabular}

a. Dependent Variable:

CSR

Berdasarkan hasil analisis data dalam tabel dapat dijelaskan hubungan antara variabel CSR secara parsial terhadap Return On Asset sebagai berikut:

a) Pengaruh CSR terhadap ROA (hipotesis 1) penerapan corporate social responsibility mempunyai nilai t : diketahui nilai $t_{\text {hitung }}$ sebesar $1,63<t_{\text {tabel }} 2,011$. Hal ini berarti bahwa penerapanCSR tidak berpengaruh terhadap kinerja keuangan (ROA).

b) Berdasarkan nilai signifikan diketahui nilai sebesar $0,11>0,05$. Hal ini berarti bahwa penerapanCSR tidak berpengaruh secara signifikanterhadap kinerja keuangan (ROA).

\section{Tabel 2. Hasil Uji Pengaruh Variabel CSR Secara Parsial Terhadap Return On Equity}

\begin{tabular}{|c|c|c|c|c|c|c|}
\hline \multicolumn{7}{|c|}{ Coefficients $^{a}$} \\
\hline \multirow{2}{*}{\multicolumn{2}{|c|}{ Model }} & \multicolumn{2}{|c|}{$\begin{array}{c}\text { Unstandardized } \\
\text { Coefficients }\end{array}$} & \multirow{2}{*}{$\begin{array}{c}\begin{array}{c}\text { Standardize } \\
d \\
\text { Coefficients }\end{array} \\
\text { Beta } \\
\end{array}$} & \multirow[b]{2}{*}{$t$} & \multirow[b]{2}{*}{ Sig. } \\
\hline & & B & $\begin{array}{l}\text { Std. } \\
\text { Error }\end{array}$ & & & \\
\hline \multirow[t]{2}{*}{1} & (Constant) & 0.249 & 0.012 & & 21.268 & 0 \\
\hline & ROE & 0.112 & 0.086 & 0.186 & 1.31 & 0.196 \\
\hline
\end{tabular}

a. Dependent Variable: CSR

Berdasarkan hasil analisis data dalam tabel dapat dijelaskan hubunganantara variabel CSR secara parsial terhadap Return On Equiy sebagai berikut: 
a) Pengaruh CSR terhadap ROE (hipotesis 2) penerapan corporate social responsibility mempunyai nilai $t$ : diketahui nilai $t_{\text {hitung }}$ sebesar $1,31<t_{\text {tabel }} 2,011$. Hal ini berarti bahwa penerapanCSR tidak berpengaruh terhadap kinerja keuangan (ROE).

b) Berdasarkan nilai signifikan diketahui nilai sebesar 0,196 $>0,05$. Hal ini berarti bahwa penerapanCSR tidak berpengaruh secara signifikanterhadap kinerja keuangan (ROE).

\section{Tabel 3. Hasil Uji Pengaruh Variabel CSR secara Parsial Terhadap Net Profit Margin}

\begin{tabular}{|c|c|c|c|c|c|c|}
\hline \multicolumn{7}{|c|}{ Coefficients $^{a}$} \\
\hline \multirow{2}{*}{\multicolumn{2}{|c|}{ Model }} & \multicolumn{2}{|c|}{$\begin{array}{c}\text { Unstandardized } \\
\text { Coefficients }\end{array}$} & \multirow{2}{*}{$\begin{array}{c}\begin{array}{c}\text { Standardi } \\
\text { zed } \\
\text { Coefficie } \\
\text { nts }\end{array} \\
\text { Beta }\end{array}$} & \multirow[b]{2}{*}{$\mathrm{t}$} & \multirow[b]{2}{*}{ Sig. } \\
\hline & & B & $\begin{array}{l}\text { Std. } \\
\text { Error }\end{array}$ & & & \\
\hline \multirow[t]{2}{*}{1} & (Constant) & 0.244 & 0.01 & & 25.315 & 0 \\
\hline & NPM & 0.373 & 0.119 & 0.412 & 3.136 & 0.003 \\
\hline
\end{tabular}

a. Dependent Variable: CSR

Berdasarkan hasil analisis data dalam tabel dapat dijelaskan hubungan antara variabel CSR secara parsial terhadap Net Profit margin sebagai berikut:

a. Pengaruh CSR terhadap NPM (hipotesis 3) penerapan corporate social responsibility mempunyai nilai t : diketahui nilai $t_{\text {hitung }}$ sebesar 3,136 $>t_{\text {tabel }}$ 2,011. Hal ini berarti bahwa penerapanCSR berpengaruh terhadap kinerja keuangan (NPM).

b) Berdasarkan nilai signifikan diketahui nilai sebesar 0,003 $<0,05$. Hal ini berarti bahwa penerapanCSR berpengaruh secara signifikanterhadap kinerja keuangan (NPM).

\section{PENUTUP}

A. Simpulan

Beberapa kesimpulan dari penelitian ini dapat dijelaskan sebagai berikut:

1. Penerapan corporate social responsibility (CSR) tidak memiliki pengaruh yang positif terhadap pengembalian aktiva atau return on asset (ROA) yang diperoleh perusahaan food and beverage yang terdaftar di BEl periode 2014-2018 karena memiliki nilai 0,680 lebih besar dari 0,05 .

2. Penerapan corporate social responsibility (CSR) tidak memiliki pengaruh yang positif terhadap pengembalian aktiva atau return onequity (ROE) yang diperoleh perusahaan food and beverage yang terdaftar di BEl periode 2014-2018 karena memiliki nilai 0,222 lebih besar dari 0,05.

3. Penerapan Corporate Social Responsibility (CSR) memiliki pengaruh yang positif terhadap Net Profit Margin (NPM) yang diperoleh perusahaan food and beverage yang terdaftar di BEl periode 2014-2018 karena memiliki nilai 0.002 lebih kecil dari 0.05 .

\section{B. Saran}

Berdasarkan kesimpulan di atas, maka penulis memberikan saran dalam penelitian ini antara lain:

1. Pada penelitian selanjutnya dapat menggunakan laporan keberlanjutan perusahaan atau sustainability reporting yang telah dikroscek oleh Global Reporting Initiative agar mengurangi resiko subjektif penilaian indeks CSR.

2. Untuk memperoleh hasil penelitian yang lebih baik, penelitian selanjutnya dapat memperpanjang periode penelitian.

3. Penelitian selanjutnya dapat menambah rasio profitabilitas karena rasio profitabilitas tidak hanya ROE, ROA, dan NPM.

4. Populasi penelitian selanjutnya tidak hanya perusahaan food and beverage tetapi dapat diperluas pada perusahaan yang terdaftar di Bursa Efek Indonesia. 


\section{DAFTAR PUSTAKA}

Sundari Sri (2011). Hubungan Corporate Social Responsibility dengan kinerja Perusahaan.Perpustakaan Unhas. Universitas Hasanuddin. Makassar.

Siregar, Chairil. 2007. Analisis Sosiologis Terhadap Implementasi CSR pada Masyarakat Indonesia, Jurnal Sosioteknologi, ITB, Bandung.

Asy'ari, Hasan, 2019. Implementasi Corporate Social Responsibility (Csr) Sebagai Modal Sosial Pada Pt Newmont, Skripsi Universitas Diponegoro Semarang.

Nugraha, Hanggara. 2011. Pengaruh Pelaksanaan Program Corporate Social Responsibility terhadap Profitabilitas pada Perusahaan Telekomunikasi yang Terdaftar padaBursa Efek Indonesia. Surabaya: Universitas Pembangunan Nasional "Veteran" Jawa Timur.

Septiana, R. A. \& Nur, E. (2012).Pengaruh Implementasi Corporate Social Responsibility terhadap Profitabilitas Perusahaan. Pekbis Jurnal, 4(2), 71-84.

Sartono, Agus. 2001. Manajemen Keuangan Teori dan Aplikasi edisi keempat Yogyakarta BEF.

Syamsuddin, Lukman. (2011). Manajemen Keuangan Perusahaan. Jakarta: Rajagrafindo Persada. 